\title{
A review of energy efficiency label of street lighting systems
}

\author{
Alberto Gutierrez-Escolar • Ana Castillo-Martinez - Jose M. Gomez-Pulido • \\ Jose-Maria Gutierrez-Martinez • Esteban Patricio Dominguez González-Seco • \\ Zlatko Stapic
}

\begin{abstract}
There are very few countries that have provisions addressing the energy efficiency of the whole street lighting system, such as Spain or the Netherlands. Nevertheless, there is not an agreement about how energy efficiency must be assessed. The Spanish Government contemplates it in the Royal Decree 1890/2008 with the goal of improving energy savings and efficiency. However, this has not obtained the expected results. Nowadays, energy efficiency of this kind of systems is assessed using a label. In the case of Spain, this label only assesses one magnitude. The contributions of this paper are two evaluation systems (kiviat diagram and pie chart) which assess five magnitudes: lamps, energy efficiency index, light pollution, renewable energy contribution, and harness of the luminous flux using dimming. After that, a survey was done to study several subjects: (1) if citizens are aware about the efficiency of street lighting systems, (2) whether the sample of colors used
\end{abstract}

A. Gutierrez-Escolar $(\bowtie) \cdot$ A. Castillo-Martinez

J. M. Gomez-Pulido · J.-M. Gutierrez-Martinez

Department of Computer Sciences, Polytechnic School,

University of Alcala, Road Madrid-Barcelona, Km 33.6, Alcala de Henares 28871, Spain

e-mail: alberto.gutierreze@uah.es

\section{E. P. D. González-Seco}

Department of Construction, School of Architecture, Polytechnic University of Madrid, Avenue de Juan de Herrera, 4, 28040 Madrid, Spain

\section{Z. Stapic}

Faculty of Organization and Informatics, University of Zagreb, Pavlinska 2, Varazdin 42000, Croatia in the label is adequate, and (3) if our proposed systems could replace the current evaluation system. Finally, the paper finishes with the conclusions of the survey.

Keywords Energy efficiency index · Kiviat diagram · Lamp · Light pollution · Pie chart · Dimming luminous flux

\section{Introduction}

At present, energy labeling is mandatory for appliances, equipment, lamps, buildings, and even street lighting systems depending on the country. Energy label is a measure which shows the purchaser of the product how economical, environmentally friendly, and/or energy saving that product is. In other words, labeling is a way of measuring and comparing energy consumption for a certain output rate (Ottens 2010).

Energy label has a significant effect on the choice of final product, possibly due to raised environmental awareness. Moreover, consumers prefer to pay more for energy efficiency in products used more frequently (Shen and Saijo 2009). Figure 1 shows the market transformation thanks to the energy label.

As it can be seen, energy efficiency labels can help a country to reduce electricity consumption. For instance, the estimation carried out by Meyers et al. (2004) indicates that it could reduce energy consumption in 2020 by $8 \%$ compared to the levels expected without any standards. This estimation is for residential appliances, but until now no one has analyzed the consequences in 
Fig. 1 Market transformation thanks to the energy label
- - - After Standards and Labels

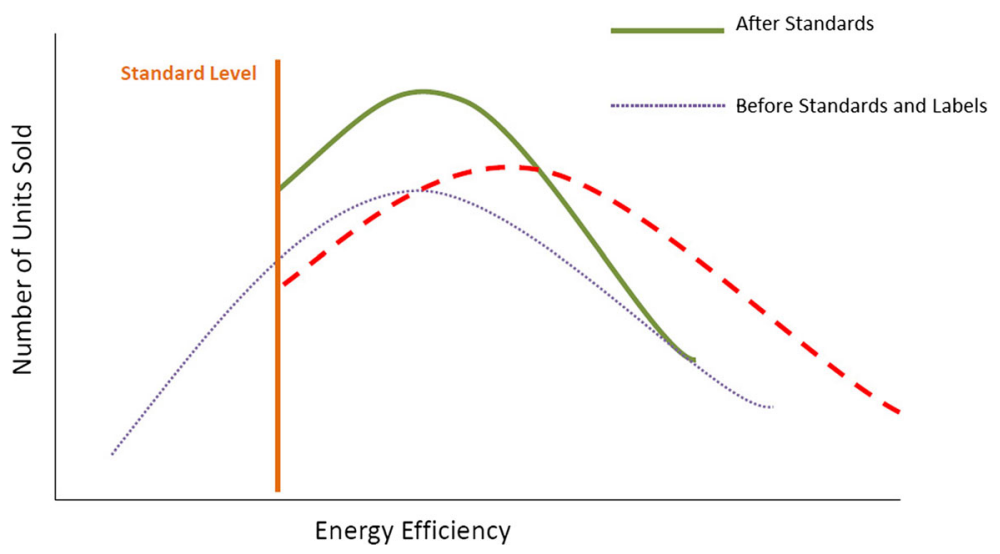

the field of energy efficiency label for street lighting systems.

There are four types of energy labels (Saidur et al. 2006); (a) seal-of-approval programs, (b) single-attribute certification programs, (c) comparative, and (d) information-disclosure. These labels are summarized as below:

(a) Seal-of-approval programs (endorsement labels): These labels offer essentially a "seal of approval" that a product meets certain pre-specified criteria. Seal-of-approval programs award or license the use of a logo to products judged to be less environmentally harmful than other similar products. Figure 2 shows US endorsement label.

(b) Single-attribute certification programs: These certify that claims made for a single-attribute of a product meet a specified definition. Such programs define specific terms such as "recycled" or "biodegradable" and accept applications from marketers for verification that their product attributes meet the program definition. If the programs verify that

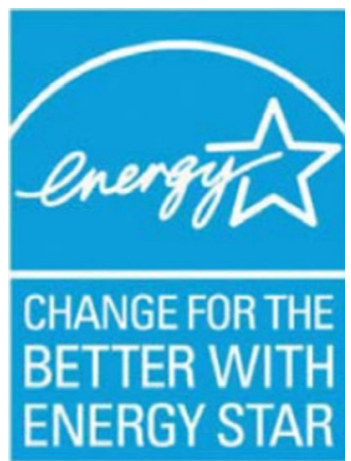

Fig. 2 Example of endorsement label the product attributes meets their definitions, the program awards the use of the logo to the marketer. Figure 3 shows EU ecolabel.

(c) Comparative labels: These labels allow the consumers to compare energy use among all available models in order to make an informed choice. Two subcategories of comparative labels have been developed around the world: one uses a categorical ranking system; the other uses a continuous scale or bar graph to show relative energy use. Figure $4 \mathrm{a}$ shows a continuous label, and Fig. $4 \mathrm{~b}$ shows a categorical label.

(d) Information-disclosure: Information-disclosure labels provide information on the technical performance of the single-labeled product and offer no simple way to compare energy performance among products. These types of labels are generally not consumer-friendly because they contain only technical information. Figure 5 shows an example of information label.

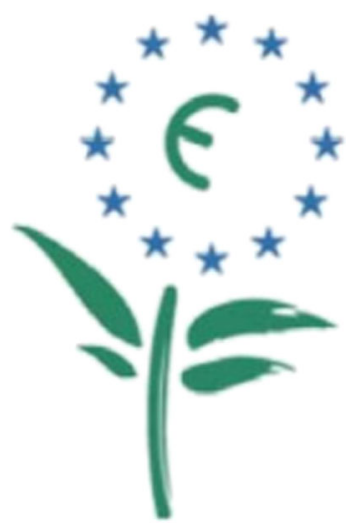

Fig. 3 Example of single-attribute certification programs 
(a) Example of continuous label

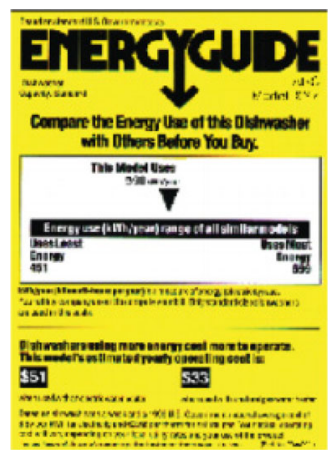

(b) Example of categorical label

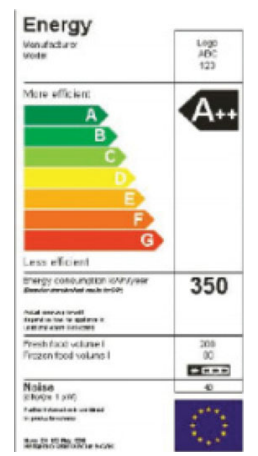

Fig. 4 Examples of label. a Example of continuous label and $\mathbf{b}$ example of categorical label

There are only very few countries that have provisions addressing the energy efficiency of the whole street lighting system (European Commission 2011), among them Spain and the Netherlands. The Royal Decree 1890/2008 (2008) was established by the Spanish Government with the goal of improving energy savings and efficiency, and, consequently, reducing greenhouse-effect gas emissions for street lighting systems. In this normative, it is defined how street lighting systems must be assessed regarding the energy efficiency. However, according to Sanchez de Miguel et al. (2014), who defined a procedure to estimate energy consumption in public electric lighting in Spain from

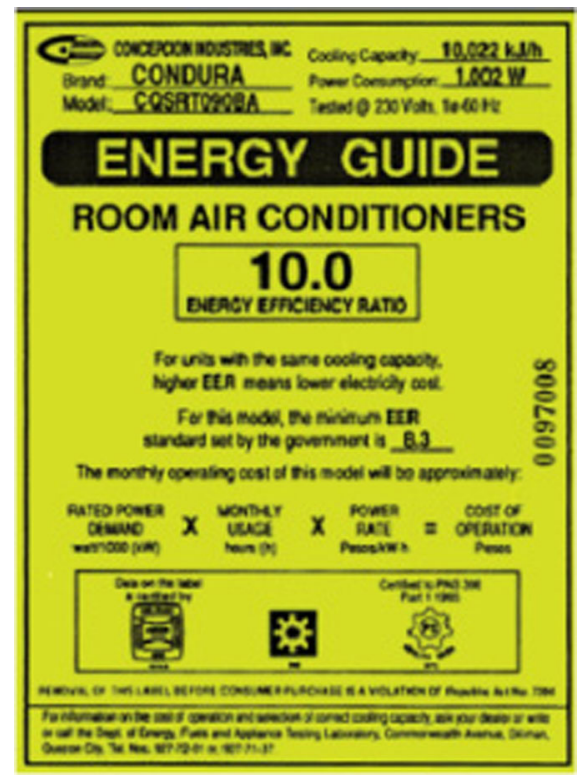

Fig. 5 Example of information label
1992 to 2012, the most populated provinces appear to have begun to stabilize the growth of expenditure on public lighting. But this does not occur in the less populated provinces where this expense continues to rise in spite of the economic crisis. In general, this energy consumption in Spain has grown constantly over the last 18 years.

Hence, the Royal Decree has not obtained the expected results, as its goal is to reduce rather than stabilize. These unexpected results might be due to two reasons: (1) the unit measured may be inappropriate or (2) labeling does not take into account enough parameters.

This paper is focused on analyzing the current energy efficiency label for street lighting system through the proposal of two evaluation labels with reference to the Spanish regulation (Royal Decree 1890/2008). For this, this manuscript has been divided as follows: The first section shows a state of the art evaluation where the different units measured to assess the energy efficiency were studied. After that, two evaluation systems for the energy efficiency label are proposed (kiviat diagram and pie chart). The third part consists of a survey which was undertaken to check if citizens are aware of the existence of the energy efficiency label and if they would be willing to accept some of these new proposals. Finally, this manuscript finishes with the conclusions.

\section{State of the art}

The first point that must be analyzed is the units measured used by different existing street lighting evaluation systems. Despite the fact that there are several ways to perform this evaluation, this section is split into two 
sections: standards adopted by different countries and other studies.

Standards adopted by countries and union of states

The European Union sets a standard called prEN 132015 (2013) which defines energy performance indicators for road lighting installations using a calculated power density (D), and a calculated annual energy consumption indicator (ECly). These indicators may be used to compare energy performance of different road lighting solutions and technologies for the same road lighting project. This standard also gives the possibility of dimming the lighting level according to parameters such as the time of the day or weather conditions. It also contains equations for calculating the installation efficacy of road lighting schemes, to be adopted as a comparative tool. However, this standard does not set minimum performance levels. It is necessary to remember that prEN 13201-5 is based on CIE 115.

The energy efficiency performance standard developed by the Canadian Standards Association (CSA Group) (2013) establishes luminaire photometric performance efficiency with establishment of maximum unit power density (UPD) values in watts per area for typical applications. The standard includes a series of tables containing maximum UPD levels for each light source, luminaire type, class of roadway with subdivided levels for pedestrian areas, and number of lanes.

Spanish standard (Royal Decree 1890/2008) establishes energy efficiency limits according to installation type; functional road lighting facilities including motorways, highways, roads, and streets for moderate to high traffic speed $(>30 \mathrm{~km} / \mathrm{h})$ and "ambient" street lighting that runs on low height (3-5 m) poles in urban areas, for pedestrian lighting, commercial streets, sidewalks, parks and gardens, historic districts, and paths with limited traffic speed $(\leq 30 \mathrm{~km} / \mathrm{h})$.

The Netherlands NL Agency (Agency \& Ministry of Economic Affairs, Agriculture and Innovation 2010) have developed a voluntary initiative that defines levels of energy efficiency for energy labels for public lighting installations with the intention of enabling objectives for saving energy to be achieved.

The aim of the standards for lighting of roads and public spaces in Australia and New Zealand Standards Australia Technical Committee (2010) AZ/NZS 1158 was to develop measures aimed at removing inefficient practices. The result was the development of a "design energy limit" which is characterized by the power consumption of the luminaire and the length of the road way.

The scope of the Bureau of Energy, Ministry of Economic Affairs of Chinese Taipei is for any streetlight product that is applying to receive the Energy Label certification. Unfortunately, the energy efficiency levels are luminaire specific only. This initiative does not include a requirement for efficiency in road lighting design (Bureau of Energy, Ministry of Economic Affairs of Chinese Taipei (Taiwan, 2012)).

The Slovenian Lighting Pollution Decree (Prelovšek et al. 2012) has enforced several changes in the fields of lighting design, installation, and maintenance. As to municipal lighting, the most far-reaching requirement is the maximum allowed annual lighting-energy consumption, which it is set at $44.5 \mathrm{kWh}$ per inhabitant per year. The other and perhaps even more important condition is the requirement of zero upward light output ratio (ULOR).

The Lighting Research Center suggests that it should measure the luminaire efficacy through LSAE parameter (Luminaire System Application Efficacy) (ASSIST 2011). The LSAE metric involves three major steps: The first is to obtain an accurate measurement of the luminaire's intensity distribution in the format of an intensity distribution file. The second is to calculate the illuminance on the task area grid. The third step is to calculate LSAE based on the illuminance, percentage of conforming cells, and the input power of the system:

LSAE $=\frac{\left(\text { ftask_conforming }\left(\frac{N_{\text {conforming }}}{N}\right)\right)}{P}$

Where task_conforming is the luminous flux inside the target task plane that meets the lighting requirements, $N_{\text {conforming }} / N$ is the ratio of conforming cells to the total number of cells in the calculation grid, and $P$ is the total input power to the luminaire.

The calculated LSAE values is for one luminaire on one pole and will vary based on the mounting height. In terms of energy savings, a higher LSAE value will generally correlate to a lower lighting power density (Narendran et al. 2010). The advantage of this evaluation methodology is that it does not include the light output falling beyond the lit-up surface. In that way the luminaires that waste light by sending it outside the litup surface are penalized. 
The first evaluation analyzed was proposed by Herring (1999) and is mainly focused on the amount of lamp's lumens per watt, but there remains the problem of adjusting for quality of service, for example, color of light, comfort, or speed road. In addition, the same author (Herring 2006) supports carbon taxes and combined policies of "green" electricity (generated from renewable energy sources) and energy efficiency. Moreover, he indicates that the goal of efficiency should be less carbon dioxide emissions without a loss of energy use; ultimately, energy growth needs to be decoupled from $\mathrm{CO} 2$ emission. In our opinion, the incorporation of renewable energy contribution into energy efficiency could be very productive.

Another way was presented by Silva et al. (2010) who developed a tool which can assess street lighting performance in the context of energy efficiency. This tool uses three indicators; one to evaluate street lighting performance and two indicators to evaluate street lighting energy efficiency.

Street lighting performance is only evaluated on the basis of the target light levels, according to the class of area to be illuminated. However, street lighting performance does not take into account parameters such as uniformity or color rendering.

Regarding the street lighting energy efficiency, there are two factors of major importance: the efficacy of the lamps and the luminaire efficiency. The efficacy of a lamp, expressed in watts per luminous unit, represents the ratio between the luminous flux emitted by the lamp and its consumed power. The efficiency of a luminaire reflects the ratio between the luminous flux it emits and that produced by the lamp. The efficiency of a luminaire varies according to the type of luminaire and its photometry.

The research conducted by Pracki (2011) proposes a new classification systems based on the installed and

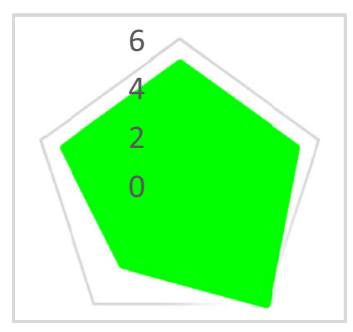

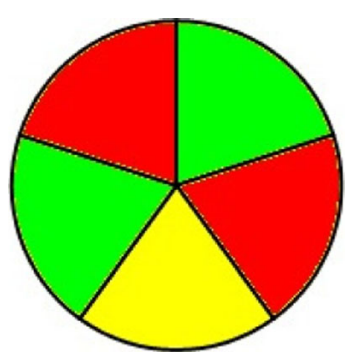

Fig. 7 Pie chart

normalized power densities of the whole street lighting system. This classification is very interesting because normalized power density depends on the following: sort of road surface; the luminous efficacy of the lighting system, which determines the energy efficiency of the lighting taking into account the watts per luminous unit $(\mathrm{lm} / \mathrm{W})$; the utilization factor, which can be expressed as a product of the light output ratio of luminaire and the road utilance; and the maintenance factor which depends on an environmental pollution conditions. In other words, this method takes into account several parameters and thus it can be used to compare the energy efficiency of design and the used of the whole street lighting systems.

Another possible option to measure the energy efficiency was proposed by Kyba et al. (2014) who established that the best way to assess street lightings is through the amount of energy consumption per kilometer per year $(\mathrm{kWh} /(\mathrm{km} \times$ year $))$.

After analyzing all the previous information, the absence of an agreement to measure the efficiency has attracted our attention. In addition, studying deeply the Spanish regulation we have realized that there are several parameters that seem too important to control, as light pollution, but they are not taken into account the

Table 1 Levels regarding the luminous efficacy according to Pracki (2011) criteria

\begin{tabular}{lll}
\hline Level & Class & Luminous efficacy $(\mathrm{lm} / \mathrm{W})$ \\
\hline 6 & A & $1 \mathrm{~m} / \mathrm{W}>150$ \\
5 & B & $150>1 \mathrm{~m} / \mathrm{W}>100$ \\
4 & C & $100>1 \mathrm{~m} / \mathrm{W}>75$ \\
3 & D & $75>1 \mathrm{~m} / \mathrm{W}>50$ \\
2 & E & $50>1 \mathrm{~m} / \mathrm{W}>25$ \\
1 & F & $1 \mathrm{~m} / \mathrm{W} \leq 25$ \\
\hline
\end{tabular}


Table 2 Levels regarding the luminous efficacy satisfying the Royal Decree

\begin{tabular}{lll}
\hline Level & Class & Luminous efficacy $(\mathrm{lm} / \mathrm{W})$ \\
\hline 7 & A & $1 \mathrm{~m} / \mathrm{W} \geq 150$ \\
6 & B & $150 \geq \operatorname{lm} / \mathrm{W}>133$ \\
5 & C & $133 \geq \operatorname{lm} / \mathrm{W}>116$ \\
4 & D & $116 \geq \operatorname{lm} / \mathrm{W}>99$ \\
3 & E & $99 \geq \operatorname{lm} / \mathrm{W}>82$ \\
2 & F & $82 \geq \operatorname{lm} / \mathrm{W}>65$ \\
1 & G & $1 \mathrm{~m} / \mathrm{W} \leq 65$ \\
\hline
\end{tabular}

setting of the energy efficiency. We want to suggest that it would be better if all parameters were included in the energy efficiency label, because in this way it is possible to analyze all the involved aspects.

\section{New evaluation systems}

Most of the previous evaluation systems only assess one parameter. Maybe, the energy efficiency would improve if the label showed more parameters, then lighting designers would be more careful when they designed this kind of installation.

Two different evaluation systems are proposed in this manuscript: the first label consists of a kiviat diagram. The second option is a pie chart with all the sections using the same percentage $(20 \%)$, but the color of each section depends on the classification. Both evaluation systems permit to compare different parameters using only one diagram. Figure 6 shows the kiviat diagram proposal.

We have considered that the kiviat diagram could be a good option to show the energy efficiency label because the values of each index are plotted on their individual

Table 3 Levels regarding the energy efficacy index

\begin{tabular}{lll}
\hline Level & Class & I $\varepsilon$ \\
\hline 7 & A & I $\varepsilon>1.1$ \\
6 & B & $1.1 \geq \mathrm{I} \varepsilon>0.92$ \\
5 & C & $0.92 \geq \mathrm{I} \varepsilon>0.74$ \\
4 & D & $0.74 \geq I \varepsilon>0.56$ \\
3 & E & $0.56 \geq I \varepsilon>0.38$ \\
2 & F & $0.38 \geq I \varepsilon>0.2$ \\
1 & G & I $\leq 0.2$ \\
\hline
\end{tabular}

axis. Moreover, this kind of diagram helps quick identification of performance evaluation (Keshtgary and Babaiyan 2012). By connecting the nodes, a distinct shape will be created which will give a global indicator that could be used during the project design to compare different solutions. Furthermore, this type of diagram has already been used to assess the performance for buildings (Schlueter and Thesseling 2009).

The second label proposed consists of a pie chart because we believe that this kind of diagram may be much clearer for citizens. Figure 7 shows one example.

From our point of view, the energy efficiency label must include as many parameters as possible. The parameters that should be considered to assess efficiency are five; lamps, energy efficiency index, light pollution, renewable energy contribution, and dimming luminous flux. The next describes how these parameters could be classified using the previous evaluation systems.

\section{Lamps}

There is no doubt that lamps are the most representative component of street lighting. There are several types of lamps which can be used on this kind of installation among which stand mercury vapor, high pressure sodium, low pressure sodium, high pressure ceramic metal halide, and led lamps. However, the second step of the EU directive 245/2009 (2009a, b), 347/2010 (2010) as well as the terms of the EU directive 2011/65 (2011) state that all mercury vapor lamps are no longer permitted to be placed on the market in the European Union. These kinds of lamps are traditionally used in town and street lighting, and still characterize the pattern of public lighting in many locations. Nevertheless, significantly more efficient and economic solutions are available that are also distinctly more sustainable.

Commission Delegated Regulation 874/2012 (2012) specifies how to estimate the energy labeling of lamps and luminaries. For this reason, we analyzed it to study the method used to make the classification. Energy efficiency class of lamps is determined on the basis of their energy efficiency index (EEI) which sets as Eq. 2.

$$
\mathrm{EEI}=\frac{P_{\text {cor }}}{P_{\text {ref }}}
$$

Where $P_{\text {cor }}$ is the power corrected for control gear losses and $P_{\text {ref }}$ is the reference power obtained from the useful luminous flux by the following equations: 
Table 4 Maximum percentage of ULOR for Spain and Croatia

Croatian standard

Spanish standard

\begin{tabular}{lllll}
\hline Surrounding & Classification zone & Maximum ULOR (\%) & Classification zone & Maximum ULOR (\%) \\
Protected & EO & 0 & Not exist & 0 \\
Natural & E1 & 0 & E1 & 1 \\
Rural & E2 & 2.5 & E2 & 5 \\
Suburban & E3 & 5 & E3 & 15 \\
Urban & E4 & 15 & E4 & 25 \\
\hline
\end{tabular}

For lamp with $\varnothing<1300$ lumen:

$P_{\text {ref }}=0.88 \sqrt{\varnothing}+0.049 \varnothing$

For lamps with $\varnothing \geq 1300$ lumen:

$P_{\text {ref }}=0.007341 \varnothing$

Analyzing this, we can appreciate that the method established by Pracki (2011) could be used for this new evaluation systems. Packri's criterion is based on the efficacy of the lamp, expressed in watts per luminous unit, because it represents the ratio between the luminous flux emitted by the lamp power. Table 1 shows the evaluation of this parameter following the classification established by Pracki (2011): (1) level class, where a high value represents a high level of energy efficiency; (2) a classification by a letter; and (3) the values of luminous efficacy of the lamp.

At first view, this classification could be considered as the best option. However, the Royal Decree 1890/2008 (2008) establishes that the minimum lumen output lamp shall be at least $65 \mathrm{~lm} / \mathrm{W}$. As can be appreciated in the Table 1, the classes $\mathrm{E}$ and $\mathrm{F}$ do not comply with the minimum requirement for Spain. Hence, we cannot propose the classification established by Pracki (2011) as such; we must modify the range of values. Table 2 shows

Table 5 Levels regarding the ULOR

\begin{tabular}{lll}
\hline Level & Class & ULOR $(\%)$ \\
\hline 7 & A & ULOR $<5$ \\
6 & B & $5 \leq$ ULOR $<9$ \\
5 & C & $9 \leq$ ULOR $<13$ \\
4 & D & $13 \leq$ ULOR $<17$ \\
3 & E & $17 \leq$ ULOR $<21$ \\
2 & F & $21 \leq$ ULOR $<25$ \\
1 & G & ULOR $\geq 25$ \\
\hline
\end{tabular}

the different classes regarding the efficacy of the lamp, taking into account the requirement of the Royal Decree.

Energy efficiency index

According to the Royal Decree 1890/2008 (2008), energy efficiency index $(I)$ is the magnitude to give the energy efficiency class for street lighting systems. To know this magnitude, it is necessary first to calculate energy efficiency ( ) which sets as Eq. 5.

$\varepsilon=\frac{S E_{\mathrm{m}}}{P}\left(\frac{\mathrm{m}^{2} \operatorname{lux}}{W}\right)$

Where $S$ is lit-up area, $E_{\mathrm{m}}$ is average illuminance, and $P$ is active power. As can be appreciated, the current evaluation system assesses three parameters $\left(\mathrm{S}, \mathrm{E}_{\mathrm{m}}\right.$, and $\mathrm{P})$. The value of energy efficiency must satisfy minimum requirements, depending of the speed limit of the road. Afterwards, I must be calculated following the Eq. 6.

$I_{\varepsilon}=\frac{\varepsilon}{\varepsilon_{\mathrm{R}}}$

Where ${ }_{R}$ is the energy efficiency reference which is established in the same Decree (2008). Table 3 shows the class regarding the energy efficiency index.

Table 6 Levels regarding the renewable energy contribution

\begin{tabular}{lll}
\hline Level & Class & Contribution (\%) \\
\hline 7 & A & $\% \geq 25$ \\
6 & B & $21 \leq \%<25$ \\
5 & C & $17 \leq \%<21$ \\
4 & D & $13 \leq \%<17$ \\
3 & E & $9 \leq \%<13$ \\
2 & F & $5 \leq \%<9$ \\
1 & G & $\%<5$ \\
\hline
\end{tabular}


Table 7 Levels regarding the dimming of luminous flux

\begin{tabular}{lll}
\hline Level & Class & Dimming (\%) \\
\hline 7 & A & $\mathrm{F} \leq 50$ \\
6 & B & $40 \leq \mathrm{F}<50$ \\
5 & C & $30 \leq \mathrm{F}<40$ \\
4 & D & $20 \leq \mathrm{F}<30$ \\
3 & E & $10 \leq \mathrm{F}<20$ \\
2 & F & $5 \leq \mathrm{F}<10$ \\
1 & G & $\mathrm{F}<5$ \\
\hline
\end{tabular}

Light pollution

This sort of pollution represents a loss. The light that is generated and disappears without having any use is a waste (Narisada and Schreuder 2004). Accordingly, poor lighting design contributes to increased carbon dioxide emissions and global warming (Gallaway et al. 2010). This magnitude should be considered to evaluate energy efficiency. To have a general idea of the wasted energy, at the end of 1990s, the amount of sky glow was equivalent to 15 million kWh of energy over Sapporo, Japan; 29 million kWh over London, UK; and 38 million kWh over Paris, France (Isobe and Hamamura 2000). The amount used for public street lighting in Helsinki, Finland, is roughly 170 million $\mathrm{kWh}$, meaning that the light wasted in Paris over a 5-day period could illuminate the whole of Helsinki for 1 day. Light sent upward is estimated to produce economic losses worth billions of euros every year (Schwarz 2003). The wasted energy also means larger $\mathrm{CO}_{2}$ emissions. In spite of the information showed for the previous researches, there is no energy efficiency label that light pollution takes into account.

New standards limit the percentage of a lamp's flux which can be directed above the horizontal plane passing through the light source in their operating positions. The upward waste light ratio (UWLR) is the proportion of the flux of a luminaire that is emitted above the horizontal when the luminaire is mounted in its position (Remande 2001). UWLR sets as Eq. 7:

$\operatorname{UWLR}(\%)=\frac{\operatorname{ULOR}(\%)}{\operatorname{ULOR}(\%)+\operatorname{DLOR}(\%)}$

Where upward light output ratio (ULOR) is the proportion of the flux of lamps of a luminaire that is emitted above the horizontal when the luminaire is mounted in its designed position and the downward light output ratio (DLOR) is the proportion of the flux of the lamps of a luminaire that is emitted below the horizontal.

Therefore, ULOR depends on the respective tilt angles, which allow improvement of the energy efficiency

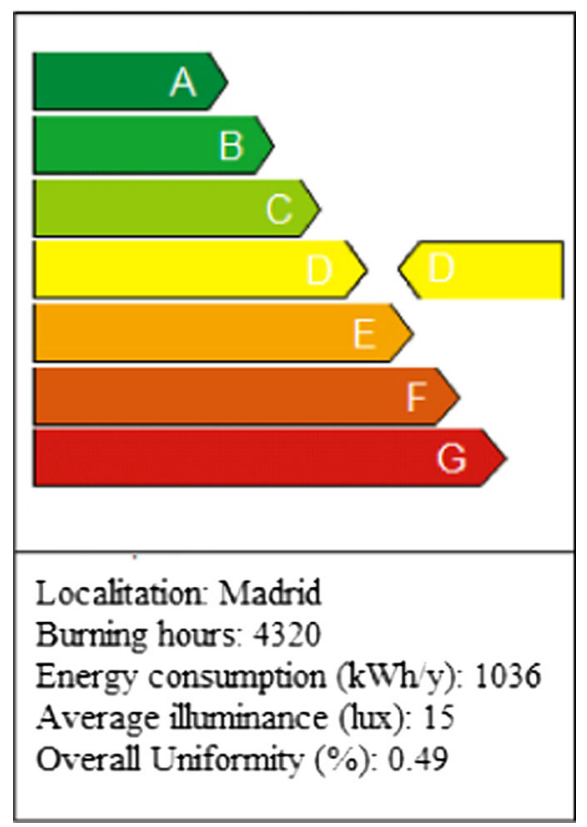

Fig. 8 Energy efficiency label of the example

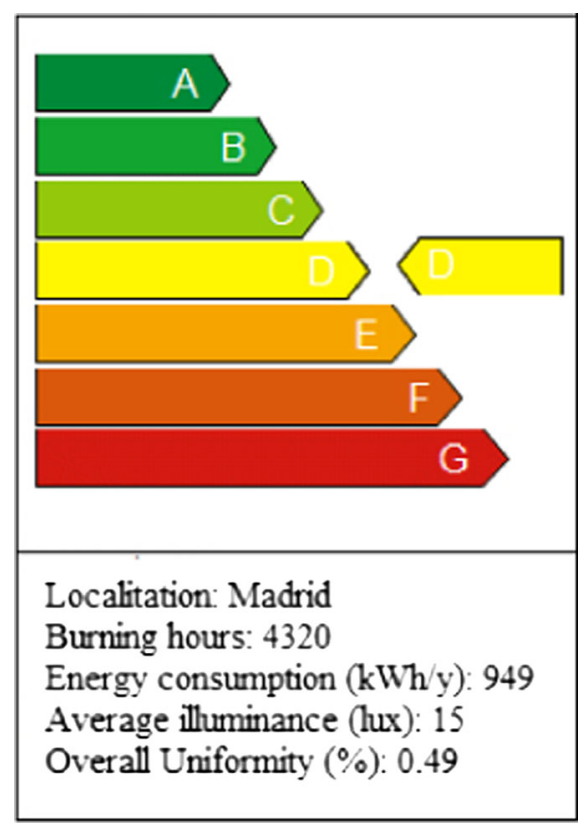

Fig. 9 Energy efficiency label (example with electronic ballast) 
(a) With electronic ballast

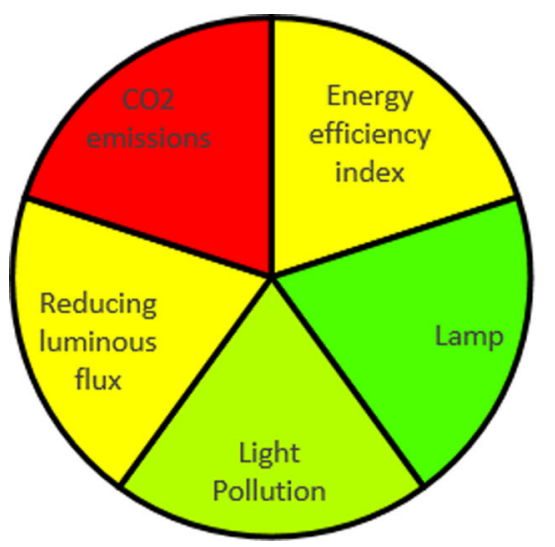

(b) Without electronic ballast

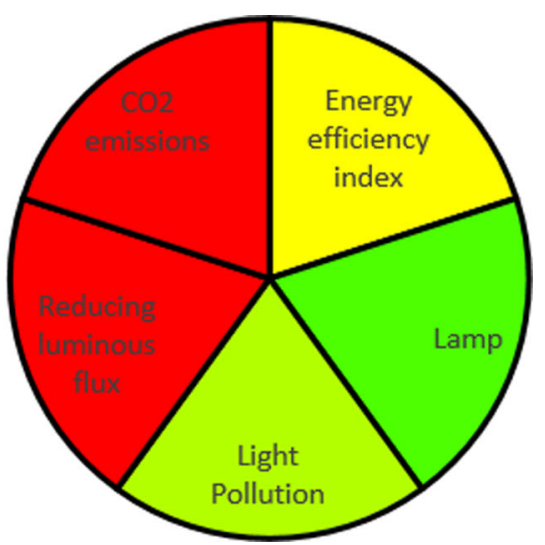

Fig. 10 Pie chart evaluation. a With electronic ballast and $\mathbf{b}$ without electronic ballast

of the installation. For example, in case of plain roads, a luminaire produces a $0 \% \mathrm{ULOR}$ at $0^{\circ}$ of tilt but it will produce an ULOR of $2.5 \%$ if the tilt angle is $10 \%$ (Smarter Scotland 2007). Nevertheless, it must be taken into consideration that, in case of a steep road, any horizontal positioned lamp will decrease the efficiency of the system.

In this point, there is no agreement about the maximum level of this magnitude. The requirements are different, depending on the country. Table 4 shows the maximum values for Spain (Royal Decree 1890/2008) and Croatia (Croatian Ministry of Environmental and Nature Protection 2013).

Although the requirements of light pollution are included in the Royal Decree 1890/2008 (2008), this

\section{(a) With electronic ballast}

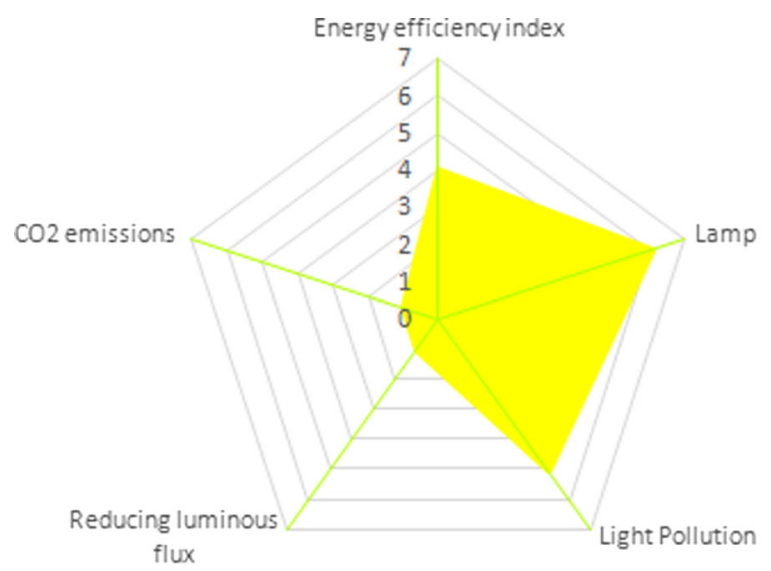

magnitude is not evaluated directly when assessing the energy efficiency. Lighting designers would be more rigorous regarding this aspect, if this parameter was considered within the energy efficiency label. Table 5 shows our proposal to assess ULOR.

Renewable energy contribution

The global need for energy savings requires the usage of renewable sources in many applications and street lighting systems are not an exception. Spain, owing to its location and climate, is one of the countries in Europe with the most abundant solar resources (Diez-Mediavilla et al. 2010). Global solar irradiation on a horizontal

\section{(b) Without electronic ballast}

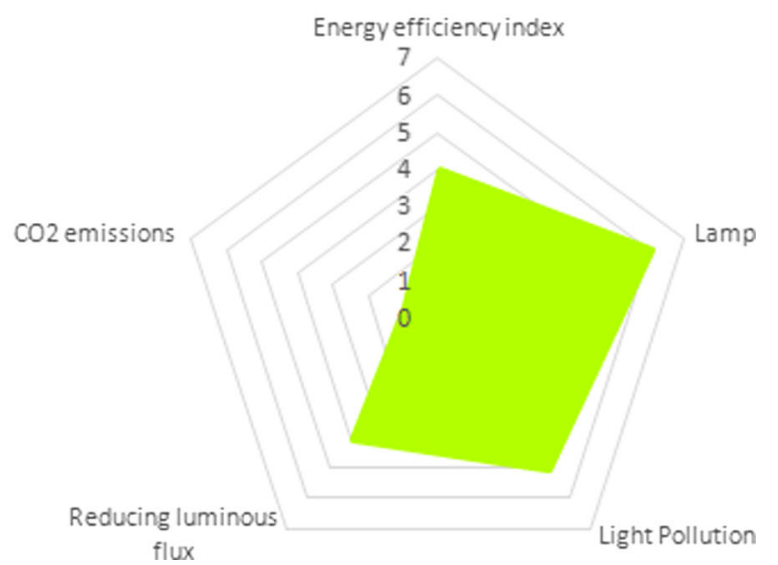

Fig. 11 Kiviat diagram evaluation. a With electronic ballast and $\mathbf{b}$ without electronic ballast 
Fig. 12 Percentage of positive answers for the first question
Percentage of positive answers

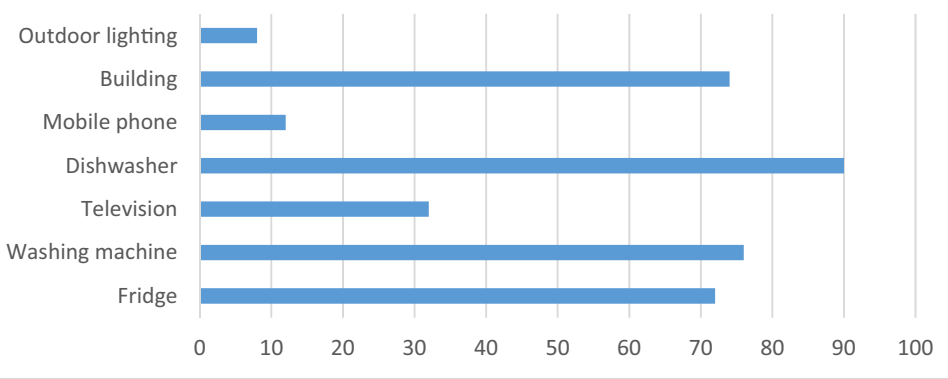

plane is estimated as being between 1.48 and $3.56 \mathrm{~kW} /$ $\mathrm{m}^{2}$ day in Spain.

Solar energy can be used for street lighting in cases of low consumption applications (Bouroussis and Topalis 2004). Maybe, the solar energy option is the best solution for autonomous street lighting systems because of its long life, easy installation, and modularity (Costa et al. 2009).

The solar energy is used to charge a self-contained battery during day time. Battery capacities are usually designed for power autonomy of 3-5 days to meet lighting loads under varying environmental conditions, and are often overdesigned (Chih-Chiang \& Pi-Kuang 2005, Notton et al. 1996). Therefore, this kind of renewable energy reduces the $\mathrm{CO}_{2}$ emissions considerably. A good example of the benefits of solar energy is the research carried out by Nunoo et al. (2010) in Ghana, achieving energy saving per day of $603 \mathrm{kWh}$. However, stand-alone street lighting systems based on the classical configuration coupling photovoltaic cells (PV) and battery cannot work all year round in regions that are far from the equator (Lagorse et al. 2009). To improve the classical system, the combination of some renewable energies is recommended.
Street lighting can also be supplied with other kinds of renewable sources or even the combination of several types of renewable sources like the research performed by Al-Fatlawi (2014) who combined solar and wind energy. Another example of this combination is the research performed by Georges and Slaoui (2011). In other words, street lighting systems which include photovoltaic systems and wind turbines typically include energy storage devices so that loads can be operated when solar energy is not available or when wind velocities are too low to generate power (Sperber et al. 2012).

However, there are not any evaluation systems that the benefits of renewable energy take directly into account. In our opinion, if the street lighting systems can reduce the $\mathrm{CO}_{2}$ emissions through renewable energy, the energy efficiency label has to show it. The criteria followed to establish the class depends on the power contribution throughout the year. Table 6 shows our proposal to assess the contribution of renewable energy.

\section{Dimming of luminous flux}

There are three devices contemplated in the Spanish standard (Royal Decree 1890/2008) able to control
Fig. 13 First illustration of the second part
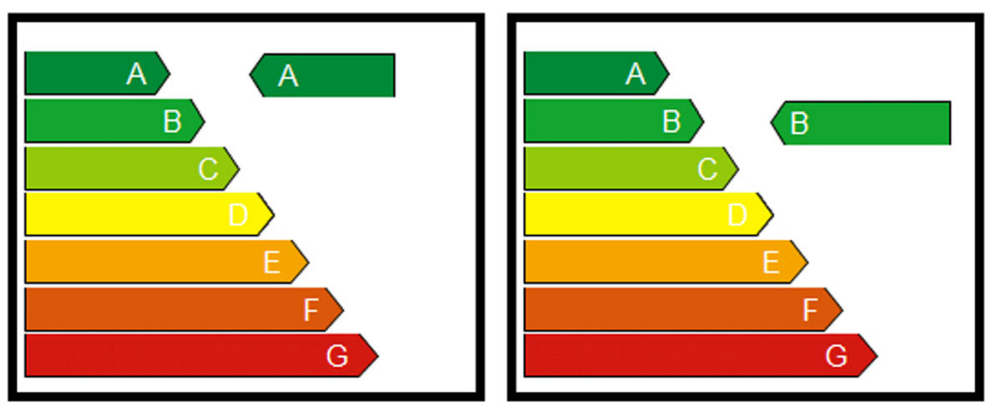


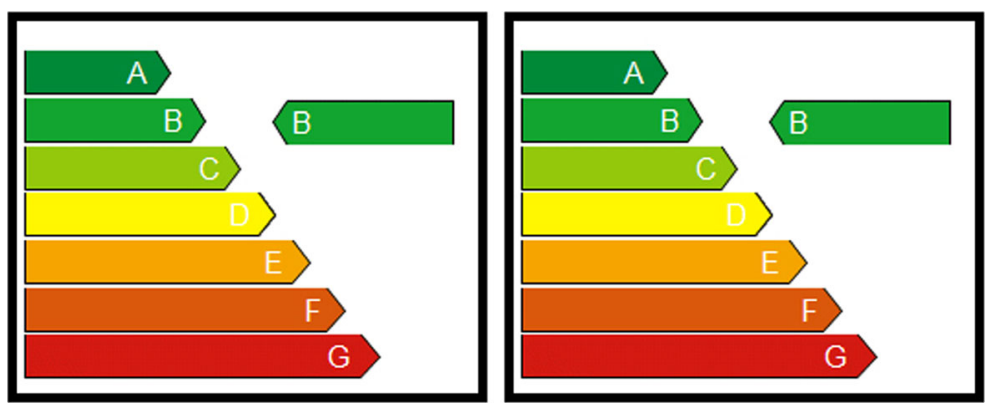

luminous flux: series inductive type ballasts for dual power level, power controlled electronic ballasts, and regulators and stabilizers in the head of the line.

In order to comply with Spanish standard (Royal Decree 1890/2008), these devices can dim the luminous flux by up to $50 \%$, provided that overall uniformity is maintained. In addition, according to Bacelar (2005), this reduction is the maximum level allowed so as not to affect on visibility of pedestrian or driver. However, the previous research has a drawback, because the only kind of lamp studied was high pressure sodium (HPS) lamps.

The main problem of using ballasts for dual power levels is that these systems act locally, requiring an adjustment device attached to each of the individual charges and also a general control system (Blanquez et al. 2012). Regulators and stabilizers are able to control the voltage according to different parameters such as number of vehicles per hour (Moghadam and Mozayani 2011), weather conditions, or the presence of pedestrians (Zotos et al. 2012). Their operation consists of hanging the input mains voltage to a variable voltage within the range from 220 to $170 \mathrm{~V}$ (Yan et al. 2009). Those changes are accompanied by variations of luminous flux and lamp power.

A good example to understand the benefits of regulators and stabilizers is the research carried out by Blanquez et al. (2012) because the power consumption was reduced by $726 \mathrm{~W}$, which represents, in its case, more than the $25 \%$ of the total energy consumption. The samples of lamps were high pressure sodium lamps (HPS) $(80 \mathrm{~W})$ and metal halide lamps (MH) $(70 \mathrm{~W})$. HPS can achieve $50 \%$ reduction in luminous flux if the lamp voltage decreased by $40.73 \mathrm{~V}$; in other words, the power savings per lamp is $29.24 \mathrm{~W}$ per lamp, which means $33 \%$ less of the power consumed. $\mathrm{MH}$ can reach a reduction of $50 \%$ luminous flux if the lamp voltage decrease in $36.89 \mathrm{~V}$; that is to say, the power savings per lamp is $30.89 \mathrm{~W}$, which means $35 \%$ less of the power consumed.

Although lighting level control devices permit a reduction of power consumed, Spanish standard (Royal Decree 1890/2008) does not specify when it

Fig. 15 Third illustration
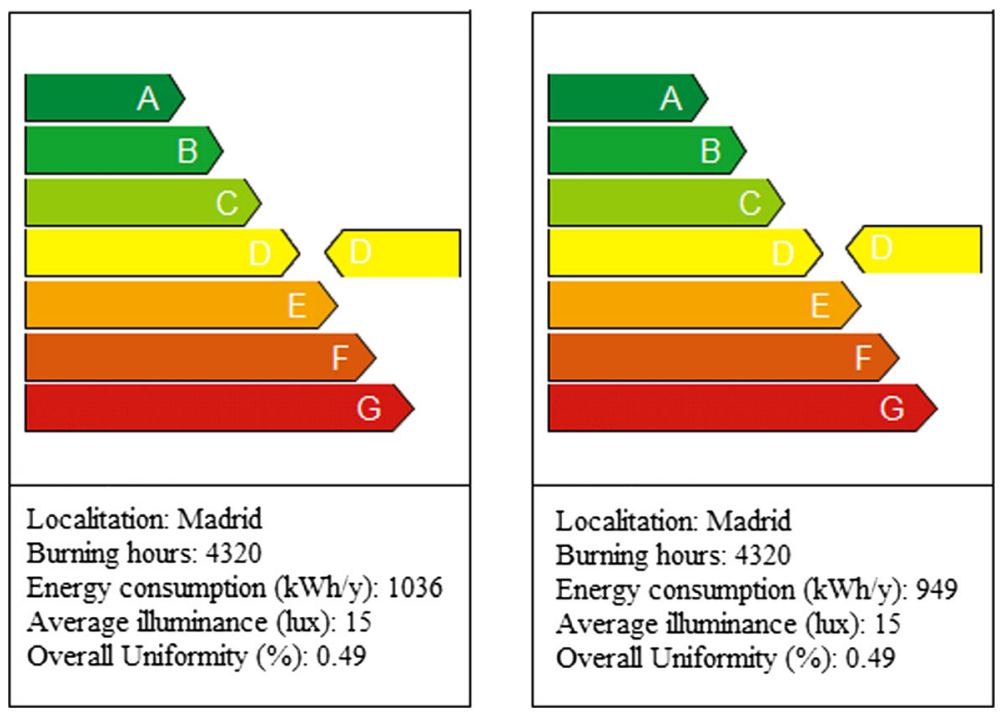

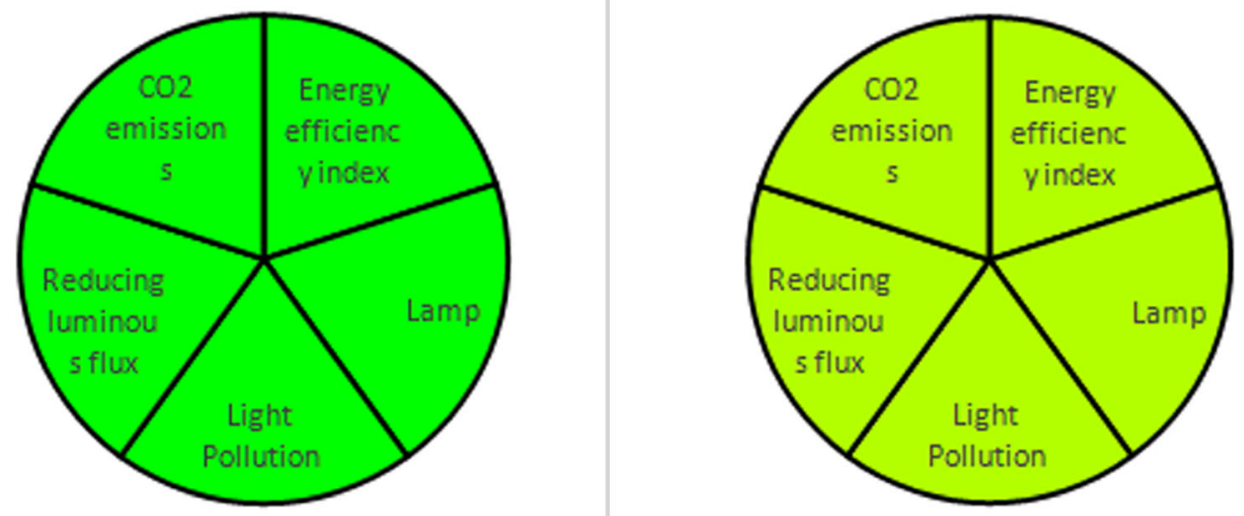

Fig. 16 Difference between A and B class

can be used. If we followed the recommendations of the Dutch ministry, dimmable road lighting systems could operate at $20 \%$ when the density of traffic at night is low, at $100 \%$ when the traffic density is high, and $200 \%$ when there is a combination of high traffic density and exceptional conditions such as fog. The conclusions were that $20 \%$ light level has no negative safety effects and is sufficient for low traffic density, but $200 \%$ light level is not justified because the cost is high and the safety improvements are marginal at best (Van Hoek 1997). Another project (Collins et al. 2002) also investigated the effect of dimming. The lighting level setting was determined as follows;
$100 \%$ when there are more than 3000 vehicles per hour, $75 \%$ when the range of vehicles is $3000-1500$, and $50 \%$ when the number of vehicles per hour is lower than 1500 .

Following both projects and observing the behavior of Spanish roads (Dirección General de Carreteras), lighting level control devices can operate perfectly from 1:00 a.m. to 5:00 a.m., because the number of vehicles decreases considerably. In this aspect, the Croatian normative (NN 114/11 Official Gazette) specifies that, if the local government does not prescribe a schedule, the street lighting must be turned off or reduced by $50 \%$ at least at 1:00 a.m.
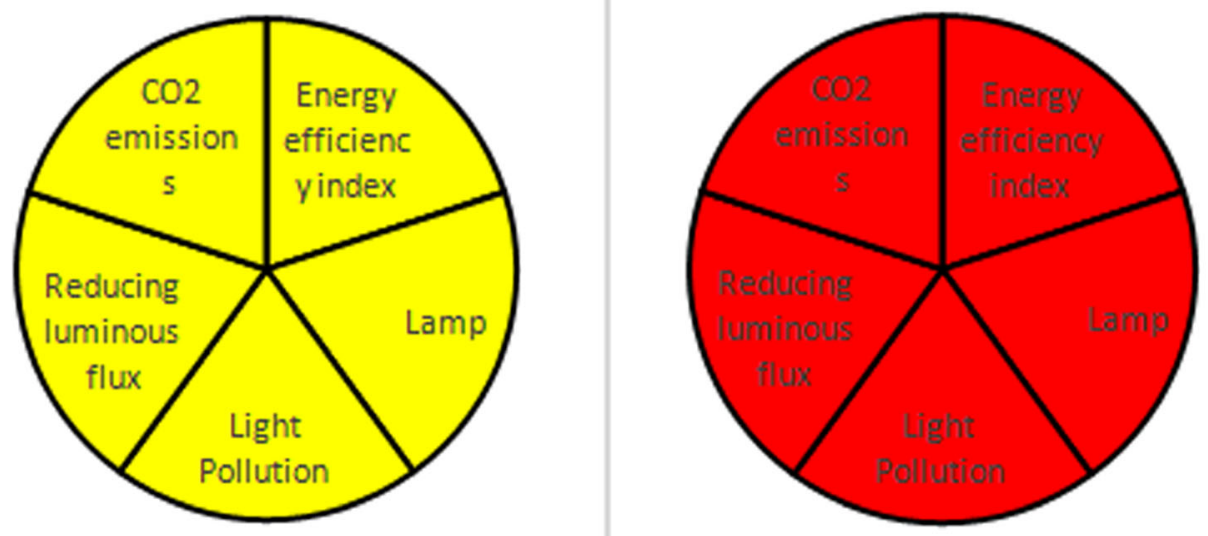

Fig. 17 Difference between level D and level G 

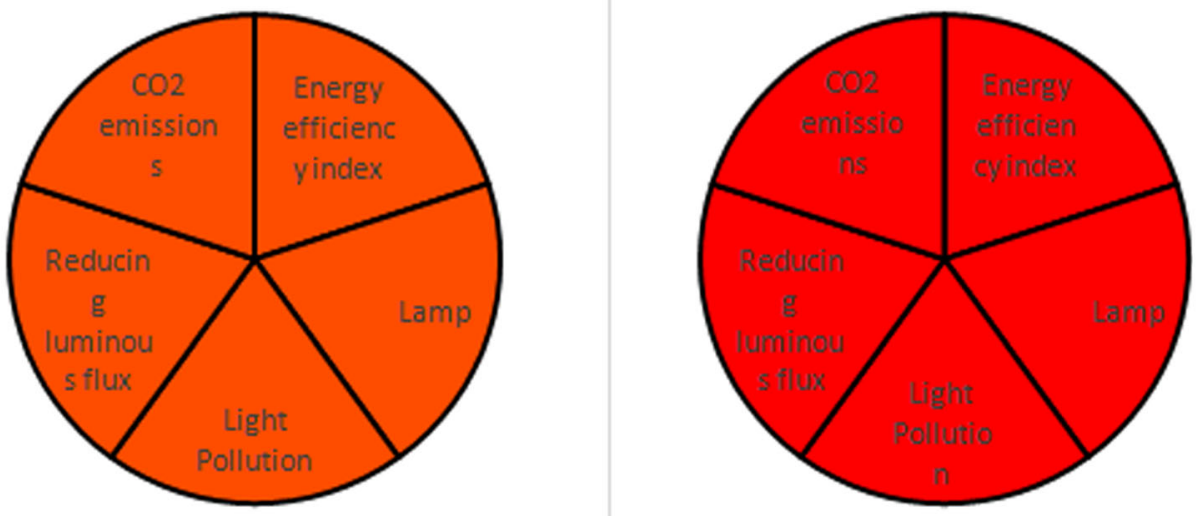

Fig. 18 Difference between level F and level G

There are a lot of examples that show the benefits of dimming of luminous flux. Nevertheless, there is not any evaluation system that directly keeps in mind this dimming when assessing the energy efficiency. Table 7 shows our suggestion to assess the class regarding the reduction of luminous flux.

\section{Example}

The best way to understand the working of these energy labels is with an example. First, it was analyzed two configurations with the current Spanish energy efficiency label and after that it was compared with our proposals to appreciate the differences.

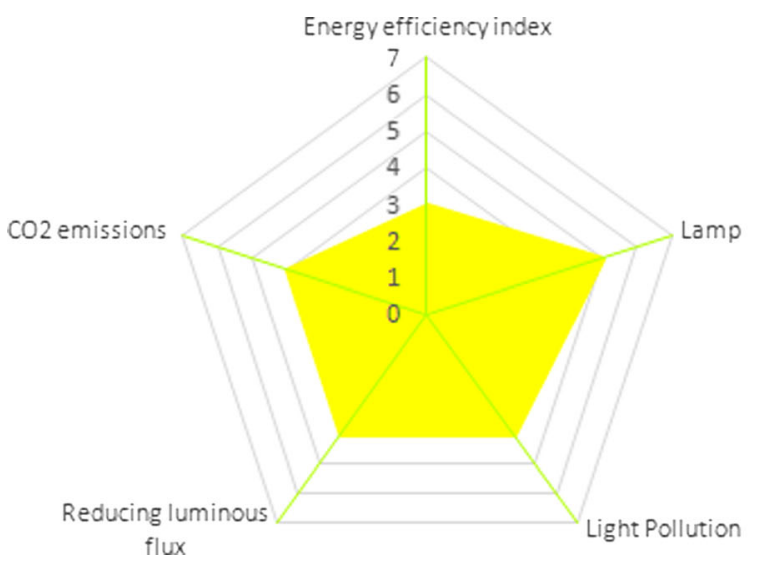

The model of the luminary studied was BRS421 T15 1xECO113-2S/740 A (Philips). The lit-up surface was 240 square meters and the mounting height was $8.5 \mathrm{~m}$. After using DIALux, the average illuminance was 15 lux. With the previous information, it is enough to develop the energy efficiency label using the current Spanish standard. The energy efficiency index was 0.7. As it can be seen in Table 3, the level would be D (Level 4). Figure 8 shows the energy efficiency label for the previous configuration.

As it can be noticed, lighting designers need few parameters to measure the energy efficiency of street lighting and they may omit some relevant parameter. On the other hand, our proposals need more information to assess the energy efficiency, for example,

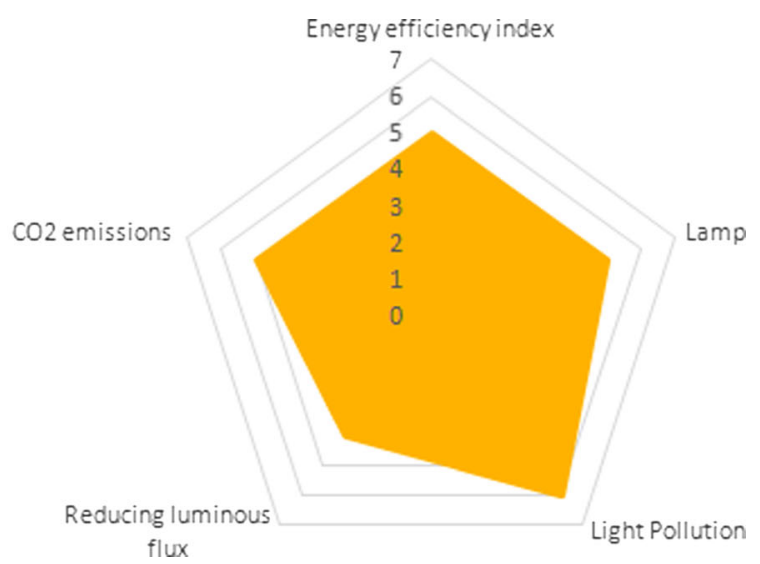

Fig. 19 Comparison between different kiviat diagrams 


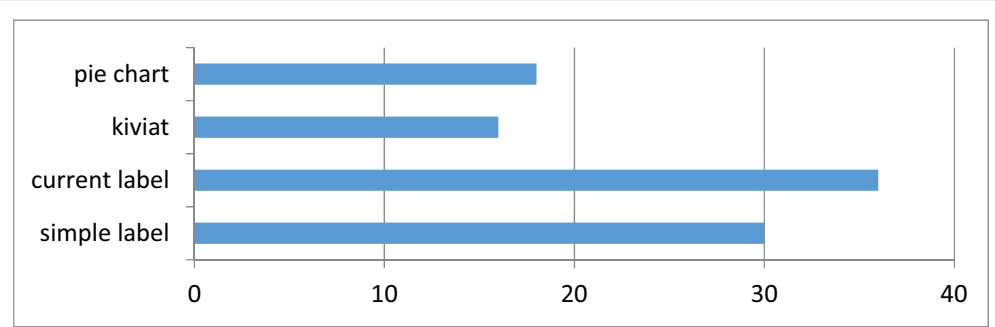

Fig. 22 Which energy label is the easiest to understand?

the five nodes gives a unique parameter which is very useful to compare different solutions.

\section{Survey}

We did a survey in Spain to check how prepared citizens are to accept these energy efficiency labels and if they are aware of the existence of an energy efficiency label for street lighting systems. The sample was composed of 50 people. The aim of the first question was to discover if citizens knew that there is an energy efficiency label for street lighting systems. We asked them if they knew which devices have an energy efficiency label. Figure 12 shows the percentage of positive answer.

Unfortunately, the percentage of citizens who knew that street lighting systems have an energy efficiency label was only $10 \%$. The survey respondents whose answer was positive for outdoor lighting were asked if they knew the unit used to measure the energy efficiency. They had three options: $\mathrm{kWh}, \mathrm{kWh} / \mathrm{km}^{2}$ year, and $\left(\mathrm{m}^{2} \mathrm{lux}\right) / \mathrm{W}$. All of them chose $\mathrm{kWh}$. This was noteworthy because the current unit in Spain is $\left(\mathrm{m}^{2} \mathrm{lux}\right) / \mathrm{W}$. In addition, awareness of energy efficiency labels on domestic appliances was high: dishwashers $90 \%$, washing machines $76 \%$, and fridges $72 \%$.

The objective of the second part of the questionnaire was to know if citizens assume that a better ranking means less energy consumption. This part is composed of three pictures, where two different systems for each energy label are shown and compared. Each comparison included two questions: Which street lighting systems is the most energy efficient? And which street lighting system consumes the least energy?

The first illustration had two simple labels with different ranks. Figure 13 shows the first picture of the second part. Surprisingly, $74 \%$ of citizens assumed that an energy label which shows a better rank represents lower energy consumption than another label with lower rank. However, this is not the case because the traditional evaluation system only takes into account the lamp power and it does not take into account dimming of luminous flux or the contribution of renewable energy.

The second illustration had two simple labels with the same rank. Figure 14 shows the picture used for the second comparison. Ninety percent of citizens replied that both images were the same and they did not have enough information to answer the question. This means that the energy efficiency label needs to include more information. In that aspect, the label established by the Royal Decree is correct, because it includes information about the position, burning hours, energy consumption, average illuminance, and overall uniformity.

The third image had two current labels with the same rank, the difference regarding the previous illustration is that, this time, the energy labels include the information

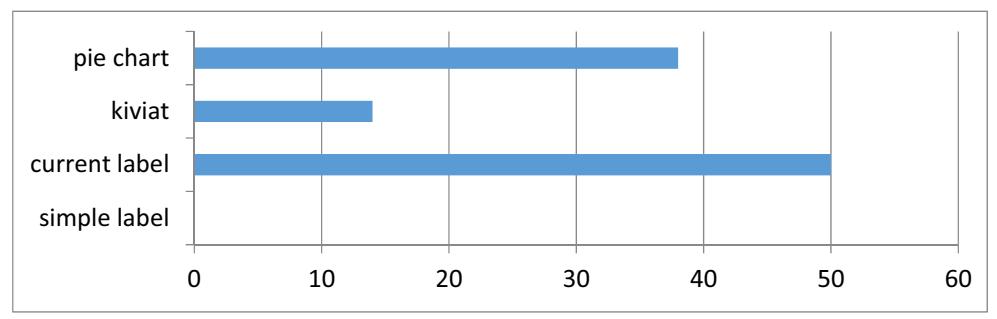

Fig. 23 Which energy label gives more detailed information? 
required by the Royal Decree. Figure 15 shows the image used. One of them shows less consumption because the system has a device to reduce luminous flux. The results obtained again show that citizens assume that when a system consumes less energy, it is more efficient. Eighty percent of survey respondents said that the label displaying less energy consumption was the system more energy efficient, when both labels had the same rank.

The aim of the third part of the questionnaire was to confirm if citizens were able to easily differentiate the colors used on the energy efficiency label and if the difference between similar levels (for example level F and level G) is too subtle to distinguish clearly. This section consists of pie charts, and the survey respondents had to reply to two questions for each image: Which street lighting system is the most energy efficient? And which street lighting system consumes the least energy?

Using the first image (Fig. 16), we wanted to discover if people were able to see the difference between level A (0-255-0) (RGB) and level B (77-255-0) (RGB). Seventy-eight percent of respondents were able to see the difference.

With the second image (Fig. 17), we wanted to understand if survey respondents were able to distinguish between level D (255-255-0) (RGB) and level G (255-0-0) (RGB). Ninety-two percent of respondents were able to see the difference.

Through the third image (Fig. 18), we wanted to see if citizens were able to see the difference between level $\mathrm{F}$ (255-77-0) (RGB) and level G (255-0-0) (RGB). Eighty-four percent of respondents were able to see that difference.

The fourth part of the questionnaire used the kiviat diagram (Fig. 19). As this label has more parameters evaluated, we asked the following: Which street lighting system is the best regarding the energy efficiency index? Which street lighting system produces the least light pollution? Which street lighting system installation is the most energy efficient? Sixty percent of respondents were able to reply correctly to all the questions. This indicates that the kiviat diagram may be too complicated for citizens without technical knowledge. Maybe, it is a good option only for lighting designers.

The last part of sheet gathers all energy efficiency labels used in the survey. Figure 20 shows the picture used. We wanted to have an overall idea of which energy label is the best for citizens.

The questions were as follows: Which energy label do you prefer to compare different street lighting systems? Which energy label is the easiest to understand? Which energy label gives more detailed information? Which energy label should be used for street lighting systems? The next figures show the results obtained (Figs. 21, 22, 23, and 24).

As it can be appreciated, our assumption that the pie chart could be a good option was not wrong addressed because the pie chart and current label obtained similar percentage (36 and $30 \%$ ).

As it can be seen, citizens are used to seeing the typical label, because they understand better the traditional label than our proposals.

As it can be appreciated, the percentage of survey respondents who chose the simple label was $0 \%$. In addition, the numerical information of the current label was accepted with great popularity. On the other hand, we believe that the kiviat diagram was not accepted because it does not show data.

As it can be seen, the current label was considered as the best option followed by the pie chart. These results validate that the energy efficiency label established by the Royal Decree 1890/2008 (2008) is adequate for citizens, but we do not believe that it is adequate for lighting designers because it has been found that street lighting systems easily meet these values in the Netherlands (Ottens 2010).
Fig. 24 Which energy label should be used for street lighting systems?

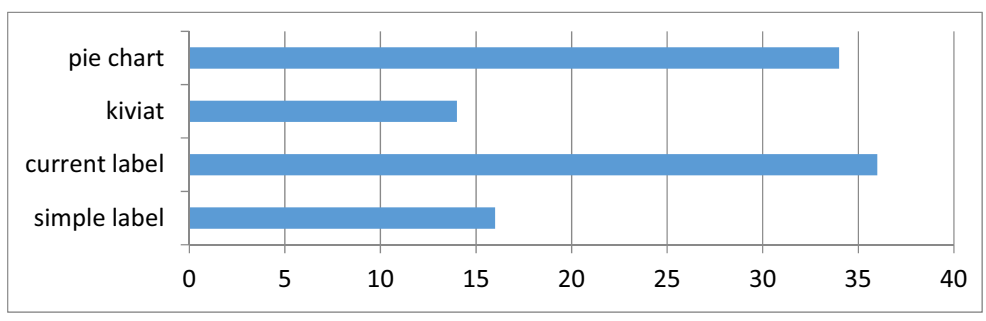




\section{Conclusions}

The results of this research are two new proposals for an energy efficiency label and a new method to assess energy efficiency for street lighting systems.

The main difference between the current evaluation system and these proposals is the number of parameters assessed. While the current evaluation system only assesses one parameter (energy efficiency index), our proposals assess five parameters: lamps, energy efficiency index, light pollution, renewable energy contribution, and dimming luminous flux.

Following the completion of this manuscript, the survey has revealed some aspects that we consider important to point out:

(1) Although the Royal Decree is mandatory from 2008 , at present, only $10 \%$ of survey respondents knew that street lighting systems must have an energy efficiency label. This means that those responsible of street lighting systems, for example, town councils, do not show the label. We propose that lamp posts would be a good place to display it. In addition, none of the respondents guessed the unit used to assess the energy efficiency correctly. They connect energy consumption with energy efficiency. In other words, they believe that energy consumption and energy efficiency is the same thing.

(2) The sample of colors used in the label is appropriate.

(3) Citizens prefer energy efficiency label with numerical data because it allows them to compare other products, systems, and so on.

(4) Finally, the current label is the best option for citizens because they do not need a lot of parameters to evaluate energy efficiency; they only need to obtain a general idea of performance. However, in our opinion, the kiviat diagram should be used for lighting designers so all aspects are taken into account at the design stage.

\section{References}

Agency \& Ministry of Economic Affairs, Agriculture and Innovation. (2010). Handbook energy labelling for public lighting. The Netherlands.

Alliance for Solid-State Illumination Systems and Technologies ASSIST. (2011). Recommendations for evaluating street and roadway luminaries. http://www.lrc.rpi.edu/programs/solidstate/ assist/pdf/ar-roadwayevaluation.pdf. Accessed 9 Dec 2014.
Bacelar, A. (2005). The influence of dimming in road lighting on the visibility of drivers. Journal of Light \& Visual Environment, 29(1), 44-49.

Blanquez, F. R., Rebollo, E., Blanquez, F., Platero, C. A., \& Frias, P. (2012). High-efficiency voltage regulator and stabilizer for outdoor lighting installations (pp. 136-142). Brasov: 13th International Conference on Optimization of Electrical and Electronic Equipment (OPTIM).

Bouroussis, C. A., \& Topalis, F. V. (2004). Optimization of potential and autonomy of a photovoltaic system for street lighting. WSEAS Transactions on Circuits and Systems, 3(5), 1392-1397.

Bureau of Energy, Ministry of Economic Affairs of Chinese Taipei (Taiwan). (2012). Energy efficiency criteria and labeling method for energy label qualified street lights.

Canadian Standards Association (2013). C653-13 Photometric performance of roadway and street lighting luminaires.

Chih-Chiang, H., \& Pi-Kuang, K., (2005). Implementation of a stand-alone photovoltaic lighting system with MPPT, battery charger and high brightness LEDs. IEEE Power Electronics and Drive Systems:1601-1605.

Collins, A., Thurrell, T., Pink, R., \& Feather, J. (2002). Dynamic dimming the future of motorway lighting? Lighting Journal, 67, 25.

Costa, M.A., Costa, G.H., dos Santos, A.S., Schuch, L., \& Pinheiro, J.R. (2009). A high autonomous street lighting system based on solar energy and leds. In Power Electronics Conference (COBEP'09) (pp. 265-273). Brazilian.

Diez-Mediavilla, M., Alonso-Tristan, C., Rodríguez-Amigo, M. C., \& García-Calderón, T. (2010). Implementation of PV plants in Spain: a case study. Renewable and Sustainable Energy Reviews, 14, 1342-1346.

Dirección General de Carreteras. Región de Murcia. Consejería de Obras Públicas y Ordenación del Territorio. Available online: http://www.carm.es/web/pagina?IDCONTENIDO= $31421 \&$ IDTIPO $=100 \&$ RASTRO $=\mathrm{c} 399 \$ \mathrm{~m} 578,31401$. Accessed 28 Aug 2015.

European Commission. (2012). Commission Delegated regulation no 842/2012 of 12 July 2012 supplementing Directive 2010/30/ EU of the European Parliament and of the Council with regard to energy labelling of electrical lamps and luminaires.

European Commission. (2011). Green public procurement street lighting and traffic lights technical background report. http:// ec.europa.eu/environment/gpp/pdf/tbr/street_lighting_tbr. pdf. Accessed 9 Dec 2014.

European Commission. (2010). Commission Regulation (EU) No 347/2010 of 21 April 2010 amending Commission Regulation (EC) No 245/2009 as regards the ecodesign requirements for fluorescent lamps without integrated ballast, for high intensity discharge lamps, and for ballasts and luminaires able to operate such lamps.

European Commission. (2009). Commission Regulation (EC) No 245/2009 of 18 March 2009 implementing Directive 2005/32/EC of the European Parliament and of the Council with regard to ecodesign requirements for fluorescent lamps without integrated ballast, for high intensity discharge lamps, and for ballasts and luminaires able to operate such lamps, and repealing Directive 2000/55/EC of the European Parliament and of the Council.

European Commission. (2009). Directive 2011/65/EU of the European Parliament and of the Council of 8 June 2011 on 
the restriction of the use of certain hazardous substances in electrical and electronic equipment.

European Normative prEN 13201-5:2013. Road lighting. Part 5: energy performance indicators.

Gallaway, T., Olse, R. N., \& Mitchell, D. M. (2010). The economics of global light pollution. Ecological Economics, 69, 658-665.

Georges, S., \& Slaoui, F. H. (2011). Case study of hybrid wind-solar power systems for street lighting. In Systems Engineering (ICSEng), 2011 21st International Conference on (pp. 82-85). IEEE.

Herring, H. (1999). Does energy efficiency save energy? The debate and its consequences. Applied Energy, 63(3), 209-226.

Herring, H. (2006). Energy efficiency a critical review. Energy, 31(1), 10-20.

Isobe, S. L., \& Hamamura, S. (2000). Light pollution and its energy loss. Astrophysics and Space Science, 273(1-4), 289-294.

Keshtgary, M., \& Babaiyan, V. (2012). Performance evaluation of reactive, proactive and hybrid routing protocols in MANET. International Journal on Computer Science and Engineering (IJCSE), 4(2), 249-254.

Kyba, C. C. M., Hänel, A., \& Hölker, F. (2014). Redefining efficiency for outdoor lighting. Energy \& Environmental Science, 7(6), 1806-1809.

Lagorse, J., Paire, D., \& Miraoui, A. (2009). Sizing optimization of a stand-alone street lighting system powered by a hybrid system using fuel cell, PV and battery. Renewable Energy, 34(3), 683-691.

Meyers, S., McMahon, J., \& McNeil, M. (2004). Realized and prospective impacts of U.S. energy efficiency standards for residential appliances: 2004 update. Berkeley: Lawrence Berkeley National Laboratory.

Moghadam, M. H., \& Mozayani, N. (2011). A street lighting control system based on holonic structures and traffic system (pp. 9296). Shanghai: In Proceedings of the 3rd International Conference on Computer Research and Development (ICCRD).

Nacrt prijedloga uredbe o standardima upravljanja rasvijetljenošću s konačnim prijedlogom uredbe (in Croatian) (2013). The Proposal of Act on Standards in Lightning Management with Final Proposal of the Act (in English). Croatian Ministry of Environmental and Nature Protection.

Narendran, N., Freyssinier, J. P., Taylor, J., Dong, T., \& Capó, R. (2010). Application efficacy for comparing energy demand in lighting applications. In SPIE Optical Engineering + Applications (pp. 77840L-77840L). International Society for Optics and Photonics.

Narisada, K. \& Schreuder, D. (2004). Light pollution handbook. Springer.

NN 114/11 (Oficial Gazette) Zakon o zaštiti od svjetlosnog onečišćenja. (in Croatian). The law on protection against light pollution (in English).

Notton, G., Muselli, M., Poggiand, P., \& Louche, A. (1996). Autonomous photovoltaic systems influences of some parameters on the sizing: simulation time step, input and output power profile. Renewable Energy, 7(4), 353-369.

Nunoo, S., Attachie, J.C., \& Abraham, C.K. (2010). Using solar power as an alternative source of electrical energy for street lighting in Ghana. In Innovative Technologies for an Efficient and Reliable Electricity Supply (CITRES) (pp. 467-471). Waltham.
Ottens J. (2010). Dutch handbook energy labelling for public lighting. http://www.nsvv.nl/download/download.aspx?id=302ec8130ae9-433f-9b5a-56eb3f4d43cc. Accessed 9 Dec 2014.

Pracki, P. (2011). A proposal to classify road lighting energy efficiency. Lighting Research and Technology, 43, 271-280.

Prelovšek, M., Bizjak, G., \& Kobav, M. (2012). English edition Public lighting energy consumption in Slovenian municipalities from 2007 to 2011. Elektrotehniški Vestnik, 79(3), 87-92.

Remande, C. (2001). Light pollution: how high-performance luminaries can reduce it. In Preserving the Astronomical Sky, 196:49.

Royal Decree 1890/2008 (2008), 14th November, by approving energetic efficiency. Regulation in outdoor lighting installations and their complementary instructions EA-01 and EA-07.

Saidur, R., Sattar, M. A., Izudin, A., \& Masjuki, H. H. (2006). Developing a comprehensive energy guide label for household appliances through consumers research survey. Journal of Energy and Environment, 5, 77-93.

Sanchez de Miguel, A., Zamorano, J., Gomez Castaño, J., \& Pascual, S. (2014). Evolution of the energy consumed by street lighting in Spain estimated with DMSP-OLS data. Journal of Quantitative Spectroscopy and Radiative Transfer, 139, 109-117.

Schlueter, A., \& Thesseling, F. (2009). Building information model based energy/exergy performance assessment in early design stages. Automation in Construction, 18(2), 153-163.

Schwarz, H.E. (2003). Light pollution control: world-wide effects of and efforts to reduce light pollution. Organizations and Strategies in Astronomy, 296:37-57. Springer Netherlands.

Shen, J., \& Saijo, T. (2009). Does an energy efficiency label alter consumers' purchasing decisions? A latent class approach based on a stated choice experiment in Shanghai. Journal of Environmental Management, 90(11), 3561-3573.

Silva, J., Mendes, J. F., \& Silva, L. T. (2010). Assessment of energy efficiency in street lighting design. WIT Transactions on Ecology and the Environment, 2010(129), 705-715.

Smarter Scotland. (2007). Guide note: controlling light pollution and reducing lighting energy consumption. http://www.scotland.gov. uk/resource/doc/170172/0047520.pdf. Accessed 9 Dec 2014.

Sperber, A. N., Elmore, A. C., Crow, M. L., \& Cawlfield, J. D. (2012). Performance evaluation of energy efficient lighting associated with renewable energy applications. Renewable Energy, 44, 423-430.

Standards Australia Technical Committee. (2010). AS/NZS 1158-6. Lighting for Roads and Public Spaces, Part 6: Luminaires.

Van Hoek, K.T. (1997). Dutch approach to energy efficient street lighting. In Proceedings of the 8th European Lighting Conference Lux Europa, Amsterdam.

Wadi Abbas Al-Fatlawi, A., Abdul-Hakim, S. R., Ward, T. A., \& Rahim, N. A. (2014). Technical and economic analysis of renewable energy powered stand-alone pole street lights for remote area. Environmental Progress \& Sustainable Energy, 33(1), 283-289.

Yan, W., Hui, S. Y. R., \& Chung, H. H. (2009). Energy saving of largescale high-intensity-discharge lamp lighting networks using a central reactive power control system. IEEE Transactions on Industrial Electronics, 56, 3069-3078.

Zotos, N., Stergiopoulos, C., Anastasopoulos, K., Bogdos, G., Pallis, E. \& Skianis, C. (2012). Case study of a dimmable outdoor lighting system with intelligent management and remote control. In Proceedings of the International Conference on Telecommunications and Multimedia (TEMU), 43-48. Chania. 